\title{
SiSTEMA ELECTORAL PORFIRISTA: EL CASO DE ChiHuahua EN I 892
}

MARIO ALEJANDRO DOMÍNGUEZ CRUZ

\section{RESUMEN}

1 1 presente artículo trata de exponer el funcionamiento del sistema político mexicano durante el régimen porfirista, en específico, el proceso electoral. La pertinencia de este trabajo recae en los pocos trabajos históricos que rescatan el tema del sistema electoral mexicano durante el periodo, y sobre todo, sus efectos y su ejercicio práctico en el estado de Chihuahua. Con fines didácticos y explicativos se toma el caso de las elecciones en Chihuahua del año de 1892, esto es porque en tales elecciones cruciales, se jugó el destino político del estado y la supremacía del clan Terrazas-Creel en la región ante el poder central. El principal interés del escrito es dejar claro que en dicho funcionamiento del sistema político, a finales del siglo XIX, seguían imperando los vínculos solidarios, el corporativismo, elementos sociales y políticos existentes desde la época virreinal, contrastando por tal, con el ideario modernizador de los reformistas liberales decimonónicos.

Palabras clave: proceso electoral, corporativismo, vínculos solidarios, liberal e individuo.

1 Licenciado en Historia por la Universidad Autónoma de Chihuahua y maestro en Historia por la Universidad Iberoamericana, Ciudad de México. Se especializa en la historia del norte de México durante el siglo XIX y principios del XX. Actualmente trabaja como profesor de cátedra dentro del Sistema del Tecnológico de Monterrey. Correo electrónico: mariosandia.89@gmail.com 
El sistema político del México porfirista operaba de una manera muy singular. Las particularidades que le eran propias surgían gracias a una pragmática centralista que beneficiaba a las élites gobernantes. En particular, el sistema electoral se guiaba bajo los mismos criterios. Las elecciones de orden estatal y federal eran llevadas a cabo bajo una cordura orgánica basada en la realidad mexicana, donde la teoría constitucional del individuo libre que elegía sus a gobernantes quedaba de lado. Por el contrario, las votaciones eran resueltas por los intereses de los grupos de poderes regionales y centrales. Si en todo caso el conceso no era posible, el voto decisivo lo tomaba la autoridad máxima del país. El presidente de México en un acto conciliador y de interés resolvía quien ocupaba el cargo político en disputa.

El funcionamiento de elecciones puede ser visto en acción con varios ejemplos a lo largo de los años y en diferentes estados de la república. Ahora se toma concretamente el caso de las elecciones a gobernador del estado de Chihuahua en el año de 1892. Para explicarlo es necesario tener como base los documentos depositados en la colección Porfirio Díaz del archivo de la Universidad Iberoamericana. Y dar contexto a las fuentes de primera mano, requiere partir de estudios previos, tal es el caso del libro del François Xavier Guerra titulado Del antiguo régimen a la Revolución, ${ }^{2}$ la investigación sobre La Revolución Mexicana ${ }^{3}$ del historiador británico Alan Knight, el libro de María Eugenia Ponce titulado La elección presidencial de Manuel González, 18781880, ${ }^{4}$ el texto de Luis Medina Peña, La invención del sistema político mexicano. Forma de gobierno y gobernabilidad en México en el siglo XIX, y por último, la obra del chihuahuense Francisco R. Almada cuyo título es Gobernadores de estado de Chihuahua. ${ }^{6}$

2 François Xavier Guerra (1989). Del antiguo régimen a la Revolución. México: FCE.

3 Alan Knight (2010). La Revolución Mexicana. México: FCE.

4 Ma. Eugenia Ponce Alcocer (2000). La elección presidencial de Manuel González, 1878-1880. México: UIA.

5 Luis Medina Peña (2012). La invención del sistema político mexicano. Forma de gobierno y gobernabilidad en México en el siglo XIX. México: FCE.

6 Francisco R. Almada (1950). Gobernadores del estado de Chihuahua. México: Imprenta de la Cámara de Diputados. 
La disposición del presente trabajo funciona bajo la siguiente lógica: primero, se desarrollarán las tesis de las previas obras académicas; en segundo lugar, a partir de las propuestas eruditas se contextualizarán las fuentes de primer orden depositadas en la colección "Porfirio Díaz"; tercero y último, tras el cotejo entre teoría y fuente histórica, se establecerán los resultados y una conclusión general.

Establecido el preámbulo de la trama, es hora de pasar a la acción. Tras leer lo escrito se observará que la teoría política liberal mexicana era una ficción avasallada por la realidad tradicional. Eran las relaciones de sangre, compadrazgo y clientelismo las que terminaban por decidir el futuro político del país. Dicho esto, se pasará a los argumentos que lo justifican.

\section{II}

En su libro Del antiguo régimen a la Revolución, el historiador Xavier Guerra trata de aclarar una de sus más importantes propuestas. Para él, el proyecto modernizador de México constaba de una contradicción, dado que abogaba discursivamente por la construcción conceptual del individuo libre, pero difícilmente posible de llevarlo a la realidad debido a la dominación del corporativismo tradicional. La descripción general de su trabajo intenta mostrar cómo modernizar la atrasada república americana; consistió en el desarrollo por parte del Estado de un sistema liberal, donde el individuo era base de la estructura política, económica y electoral. La idea trataba de disfrazar a la nación mexicana con los atavíos de las más avanzadas naciones europeas. En la siguiente cita, Guerra describe el principal problema de México en el siglo XIX:

En la base de esta sociedad existen vínculos de hecho que hemos descrito: familia, clanes, comunidades campesinas, haciendas tradicionales, tribus indígenas no integradas, etcétera. En el seno de esas unidades, la palabra clientela no puede convenir a relaciones 
muy densas y tradicionales, sin verdadera libertad de elección, debido a una dependencia social o a un sistema de valores que da la prioridad al grupo, o a ambos a la vez.?

A partir de los vínculos solidarios, el proceso electoral tomaba forma y sentido. Sin embargo, estos podían hacer que los comicios fueran conflictivos y difíciles de resolver. En cada región del país existían grupos políticos en constante confrontación. El año de elecciones significaba una lucha entre grupos de poder que se disputaban el control político de su región.

La interpretación de Xavier Guerra, en cuanto al funcionamiento de la política mexicana, recuerda en varias ocasiones la propuesta académica de Fernand Braudel. Y sucede, puesto que los vínculos sociales que unen y forman la política mexicana, para Guerra, actúan de manera prolongada y en larga duración. ${ }^{8}$ Estos aparecieron durante la época virreinal y se prolongaron a lo largo del siglo XIX. Resultan ser los grandes enemigos a combatir por las reformas liberales decimonónicas y la constitución de 1857, sin embargo, y a pesar del intento de erradicación, los mismos perduraron. De hecho, son estos, los que permiten la formación y vinculación de las relaciones políticas del nuevo sistema político posrevolucionario.

7 Guerra, 1989, p. 153.

8 A grandes rasgos, el proceso de larga duración de Fernand Braudel propone la existencia de fenómenos profundos, graduales y latentes que marcan la evolución cultural del hombre y su entorno físico y natural. En la opinión de Braudel, el proceso de la larga duración solo es afectado de manera superficial a causa de las acciones humanas; en su estructura profunda sigue desarrollándose sin complicaciones. La duración de tales procesos puede durar un lapso prolongado que se extiende a siglos. En este caso, la larga duración es una herramienta metodológica que auxilia al investigador a entender la mentalidad y el comportamiento cultural de la sociedad mexicana en el transcurso del tiempo. A continuación se rescata la siguiente cita de Braudel explicando su propuesta: La segunda, mucho más útil, es la palabra estructura. Buena o mala, es ella la que domina los problemas de larga duración. Los observadores de lo social entienden por estructura una organización, una coherencia, unas relaciones suficientemente fijas entre realidades y masas sociales. Para nosotros, los historiadores, una estructura es indudablemente un ensamblaje, una arquitectura; pero, más aún, una realidad que el tiempo tarda enormemente en desgastar y en transportar. Ciertas estructuras están dotadas de tan larga vida que se convierten en elementos estables de una infinidad de generaciones: obstruyen la historia, la entorpecen y, por tanto, determinan su transcurrir (Braudel, 2007, p. 7.). 
Por lo pronto, la interpretación de Guerra en cuanto a la agenda de acción de los liberales en contra de la tradición:

[...] el hombre antiguo, inmerso en los múltiples vínculos de las sociabilidades antiguas, es por esta razón un hombre que no ha llegado a la dignidad de individuo sin más lazos que los surgidos de su libre voluntad, la acción que deben llevar a cabo los que han alcanzado esta dignidad -la élite conquistada por la nueva culturadebe consistir en romper esos vínculos. De ahí el camino que todos los regímenes liberales han recorrido: primero, la supresión jurídica de todos los privilegios y estatutos particulares... Por la desamortización de los bienes de mano muerta... Finalmente, la tercera etapa, la lucha contra el sistema de valores de la sociedad, del que de la iglesia era garantía y autoridad suprema. ${ }^{9}$

En todo caso, la monumental obra Del antiguo régimen a la Revolución, intenta establecer la existencia dilatada de una realidad política sui generis. Por un lado, se encontraban los estatutos institucionales, legales y correctos de cómo desarrollar la labor política, y por el otro, las solidaridades tradicionales heredadas por largas generaciones, las cuales eran mal vistas y como un elemento indeseable por los liberales mexicanos. En tal situación la moneda tenía dos lados. La intentona de modernización de la política mexicana se enfrentó al siguiente dualismo:

Se oponen dos mundos, dos representaciones de la relaciones entre lo social y lo político. En el antiguo Régimen, el de los vínculos y las solidaridades antiguas, la sociedad está formada por cuerpos -podríamos decir, por actores colectivos institucionalizados-... En el mundo político moderno, la política se ha convertido en un ámbito autónomo de actividad y para entrar en él es necesario construir una sociedad abstracta de individuos iguales, una ficción, el pueblo, que únicamente se hace real cuando el individuo abstracto se convierte en un ser real con el voto. ${ }^{10}$

9 Guerra, 1989, p. 163.

10 Guerra, 1989, p. 164.

Chihuahua Hoy, año is, Núm. is (enero-diciembre, 2017) 
Por su cuenta, el historiador británico Alan Knight y su investigación sobre la Revolución mexicana llegan a coincidir con Xavier Guerra, muy a pesar de que sus respectivas interpretaciones sobre el tema han estado siempre enfrentadas. Knight llega a la conclusión de que el Estado mexicano que encabezaba Porfirio Díaz era parte del selecto grupo de lo que llama "democracias artificiales”. Pertenecer a tales democracias significa, en la opinión del académico de la Universidad de Oxford, ejercer una práctica política totalmente distanciada de la teoría liberal tan predicada en la constitución y códigos legales. En las propias palabras de Alan Knight:

El México de Díaz era un miembro prominente de la gran tribu de "democracias artifíciales," Estados que en la práctica política disentía radicalmente de la teoría liberal a la que se sujetaba. ${ }^{11}$

A lo que respecta de la estructura social del México porfirista, Knight, apunta a la construcción de una pirámide donde en el punto más álgido se encontraban los liberales mexicanos del centro del país. Estos eran una élite educada, progresista, cosmopolita y urbana, desentendida de la realidad social de las clases inferiores a ellos. Con un proyecto teórico europeo y americano disonante con la hasta entonces operante tradición mexicana, determinados a imponer su visión sobre el resto de la estructura. Su libro dice:

Los liberales: se trataba también de un nuevo tipo: urbano, cosmopolita, articulado e ilustrado... los científicos fueron progresistas en lo económico; defendieron los principios del "progreso" y, al parecer fueron capaces de inculcar una actitud similar entre sus subordinados. ${ }^{12}$

Antes de terminar con la interpretación de Alan Knight es importante mencionar, que al igual que Guerra, llega a la conclusión de la existencia de un dualismo en la realidad mexicana. Las élites

11 Knight, 2010, p. 47.

12 Knight, 2010, pp. 51-52. 
porfiristas estaban determinadas a construir un gobierno fuerte y desarrollar una economía moderna, pero poco resueltos a cambiar las estructuras sociales. Lo anterior siguiere una sociedad mexicana abierta a ciertos aspectos, pero conservadora y tradicional ante otros. Es aquí donde entra la idea de los vínculos solidarios, pues estos prevalecen ante la innovación. La convivencia de la modernidad con la tradición es asentada en la obra de La Revolución mexicana. La identifica como:

[...] a una especie de "fuerte gobierno conservador" comprometido con la construcción del Estado y el desarrollo económico, pero débil en la solución de un problema inherente e insoluble, moderniza sin cambiar... las estructuras sociales. ${ }^{13}$

Si se retoma el trabajo de la historiadora Eugenia Ponce sobre las elecciones del año de 1880, se debe de considerar el proceso electoral como una mesa de negociación. De un lado se encontraba el centro del país y su élite política, por el otro, las élites periféricas. Si un candidato deseaba alcanzar un cargo público, antes, debía de lograr alianzas lo suficientemente fuertes con las élites políticas, económicas y militares regionales, de no lograrlo, se peligraba de una inestabilidad política. En la introducción de su trabajo, Ponce trata de dejar claro el funcionamiento de los comicios en México. Más que un proceso real y correctamente ejecutado, era una escena planeada, donde atrás del telón, estaban los que verdaderamente elegían:

Constituye [La investigación] una aportación al estudio del sistema electoral mexicano de finales de siglo XIX, en ella se observa que, como en épocas anteriores, las elecciones jugaron un papel central en la política mexicana, no necesariamente como ejercicios efectivos para elegir funcionarios, sino como rituales políticos y detonadores de debates y agitación popular. Este aspecto de las elecciones no pasó inadvertido para los observadores y políticos contemporáneos, quienes frecuentemente consideraron el sufragio y los procedimien-

13 Knight, 2010, p. 69.

Chinuahua Hoy, año is, Núm. Is (ENero-diciembre, 2017) 
tos a su alrededor, como un mero ritual en el que el gobierno y sus funcionarios representaron una escena democrática. ${ }^{14}$

Como ejemplo para evidenciar su postura, la historiadora escribe sobre el apoyo que recibió Manuel González de sus aliados norteños para afianzarse como el candidato indicado para suceder a Díaz. Su texto llega a mencionar nombres como Francisco Naranjo, Servando Canales y Carlos Diez Gutiérrez, mismos que eran cabecillas políticas y militares de sus regiones. ${ }^{15}$ La red de amistad entre todos estos hombres, se consiguió al paso de los años y las batallas, la mayoría de ellos tuvieron en común una vida militar muy activa, además de una vida política prestigiosa y respetada. Amistad, compadrazgo y cacicazgos fueron los elementos decisivos para la actividad política mexicana del siglo XIX y XX.

Continuando con el desplegado de ideas, Eugenia Ponce, logra distinguir la contradicción del sistema político mexicano. Dicha anomalía radicó en la inoperatividad de un sistema basado en la elección popular de gobernantes, en una nación, donde la mayoría de los ciudadanos carecía de los conocimientos básicos del funcionamiento del proceso. Como consecuencia, se estableció peculiaridad que daba el control de la "democracia" a un grupo minoritario de políticos. ${ }^{16}$

La historiadora Eugenia Ponce llega a la misma conclusión que Xavier Guerra y Alan Knight. Según ella es posible establecer una comparativa entre el ideal de elecciones democráticas y su práctica mexicana. La consecuencia es la de evidenciar una disparidad enorme entre ambas. La realidad de las elecciones mexicanas estaba marcada por su poco alcance territorial, los requisitos para los electores y una serie de elementos comunes en la tradición hispanoamericana, como lo fueron la manipulación, el control y el patronazgo.

No muy lejos de las revisadas interpretaciones históricas, se encuentra el libro La invención del sistema político mexicano del

14 Ponce Alcocer, 2002, p. 1 (las cursivas son del autor).

15 Ponce Alcocer, 2002, p. 5.

16 Ponce Alcocer, 2002, p. 8. 
investigador Luis Medina Peña. Su trabajo resulta ser un extenso y detallado análisis histórico del surgimiento del Estado mexicano a lo largo del siglo XIX. Uno de sus intereses es el rebatir la enfoque tradicional del régimen porfirista de puño duro, fuerte y centralizado, y el de procurar una nueva perspectiva que alega el gobierno de Díaz "como el régimen de un caudillo liberal, unificador de los múltiples caudillos y caciques regionales..."17 A pesar de sus intentos de originalidad, el trabajo de Medina Peña retoma la explicación de los llamados vínculos solidarios y políticos como los que viabilizaron las alianzas entre las élites, lo que lo asemeja a los trabajos previamente citados.

Para la investigación de Medina Peña, el gobierno del presidente Díaz buscó reequilibrar las tensiones entre centro-periferia a partir de una serie de reformas políticas y atribuciones especiales al poder legislativo que lo volvieron en un ideal intermediario entre grupos dominantes. Su política conciliadora trató de promover la convivencia entre el ejecutivo federal y sus secretarías de Estado con los gobiernos y congresos estatales además de los poderes municipales. Justo del libro de Luis Medina Peña se rescatan las siguientes palabras, en extremo relacionadas con el presente párrafo sobre la política del presidente Díaz:

El objetivo último no era por lo tanto, transformar el viejo equilibrio sino más bien reequilibrar las tensiones esenciales con una nueva y mejor articulación entre poder federal (presidencia y secretarios de Estado), poderes regionales (gobernadores y asambleas regionales), y poderes locales (municipios), atribuyendo al Parlamento (Cámara de Diputados y Senado) un nuevo papel, de intermediación. Hasta la década de 1890, y es oportuno afirmarlo, no se encuentran excepto en raras ocasiones, intervenciones federales directas en la esfera propia de los estados y más concretamente tentativas de control sobre los municipios y las autoridades regionales intermedias (jefes políticos) a la vez que se observa la afirmación de dos esferas independientes, la de los estados y la del Estado federal. ${ }^{18}$

17 Medina Peña, p.154.

18 Medina Peña, 2012, p. 159.

Chihuahua Hoy, año is, Núm. is (enero-diciembre, 2017) 
Entre otras de las formas en que operaba la política porfirista, el historiador Medina Peña rescata la reconfirmación de los caudillos regionales como gobernantes de sus zonas. Dicha asignación del cargo estaba sujeta a partir de una muestra clara de lealtad del gobernante al poder central, de no ser así, este podía enfrentarse en una intensa lucha, que en ocasiones llegaba a ser armada y violenta con las facciones regionales opositoras apoyadas por el gobierno central. ${ }^{19}$ Fue de tal manera que los vínculos solidarios y de lealtad política, tan comentados desde el principio del texto, pacificaron y armonizaron el ambiente político de la época, y sin ellos, la operatividad del sistema de gobierno mexicano no podría ser entendido.

En resumen. Se considera importante por parte de quien escribe, rescatar la perspicacia de los autores antes citados al contextualizar del sistema político mexicano decimonónico y su procedimiento electoral. En las tres obras históricas no se deja pasar de lado el juego de intereses entre centro y periferia, además del preponderante papel de los vínculos solidarios, que sin duda, en aquel entonces como ahora eran y son tan importantes para el sentido político de México. A pesar de la cortedad del análisis de los textos, con él es posible establecer la básica funcionalidad de la sucesión de gobernantes en el México contemporáneo.

\section{IV}

Esclarecido el funcionamiento del sistema político mexicano, se pasa al estudio de caso. En el año de 1892, el estado de Chihuahua vivió una acalorada y conflictiva jornada electoral. El ojo del huracán lo conformaban los dos grupos de más poder regional. Por un lado estaba el famoso clan Terrazas-Creel comandado por el señor Luis Terrazas, que desde 1884 habían perdido el poder político del estado y veían en las elecciones de 1892 la oportunidad de volver a la cima política. Del otro, estaba el grupo contrincante del gobernador Lauro Carrillo y el general Carlos Pacheco, que consideraban las elecciones del '92 como una amenaza real

19 Medina Peña, 2012, p. 159. 
del retorno del cacicazgo político de Luis Terrazas. El regreso de la supremacía Terrazas al estado de Chihuahua, desequilibraría de nuevo el contexto político, afectando los intereses de los grupos rivales. Conservar el statu quo era para el gobernador Lauro Carrillo una prioridad, tanto, que la posibilidad de reelección era una de las primeras opciones.

La gubernatura de Lauro Carrillo, cuya duración fue de 1888 a 1892, se jactó de una personalidad antiterracista, y apegada a la política porfirista. Era el contrapeso del centro del país que obstaculizaba la hegemonía regional de Luis Terrazas. Entre otras cosas, el gobernador Carrillo, era apreciado desde el centro de la república debido a su esfuerzo en la liquidación de las invasiones apaches, lo que significó materialmente el progreso de la economía estatal y el aumento de la recaudación de impuestos. Desde el principio fue considerado por Díaz como un aliado, y esto en gran parte fue posible gracias a la intervención del general Carlos Pacheco, aliado político que ambos tuvieron en común. ${ }^{20}$ En el libro de los gobernadores de Chihuahua, el historiador Francisco R. Almada lo describe así:

Representó en los negocios públicos de Chihuahua la fuerza política del General Carlos Pacheco, apoyado por el gobierno del general Porfirio Díaz, frente a la tendencia perpetua del general Luis Terrazas y los suyos de volver a todo trance en adueñarse de los destinos del estado y restablecer el cacicazgo que había subsistido durante 24 años, salvo cortas interrupciones [...] La administración del señor Carrillo marcó el principio de la centralización del gobierno de acuerdo con las reglas impuestas por el régimen porfirista. ${ }^{21}$

Sin embargo, la crisis vivida bajo su cuatrienio en el municipio de Tomóchic, ${ }^{22}$ hicieron que perdiera la simpatía y el apoyo del

20 Almada, 1950, p. 413.

21 Almada, 1950, pp. 408-409.

22 A finales del año de 1891, el pueblo serrano de Tomóchic, Chihuahua, se sublevó contra el gobierno central y estatal debido a la imposición de una nueva autoridad local, aunque las versiones oficiales siempre señalaron el fanatismo religioso como única causa. La designación del nuevo presidente seccional era un movimiento político 
centro de país, una de las principales causas de su fracaso de reelección. El desgaste del apoyo de Porfirio Díaz a Carrillo se debió más que nada a su torpeza en controlar la aludida revuelta. En su libro, el historiador Almada comentó que su más grande error fue que "apoyó discrecionalmente a las autoridades regionales, sin haber tratado de averiguar la razón o sinrazón del descontento de los serranos chihuahuenses". ${ }^{23}$ Aunado, reflexionó que otra causa de la caída del gobernador Carrillo fue su incapacidad para evitar que la agitación se extendiera por todo el estado. ${ }^{24}$

Tras enterarse el grupo Terrazas-Creel de la tentativa de reelección del gobernador Lauro Carrillo, comenzó por partes de sus miembros una intensa campaña mediática y política en su contra. Las acciones iban desde una fuerte crítica editorial en el periódico de línea terracista llamado El Norte, mismo que era dirigido por el licenciado Pablo Ochoa, amigo y aliado de Terrazas, pasando por la fundación del Club Central Político y el envío constante de cartas al presidente Porfirio Díaz, abogando por la legalidad y el antirreelecionismo. ${ }^{25}$ Dichas cartas sobreviven hoy en el archivo de la Universidad Iberoamericana y son los documentos que sirven de cimientos para este trabajo. Se tomaron cinco de estas cartas y la mayoría son del grupo de oposición del gobernador Carrillo.

Con la encendida jornada electoral en su máximo esplendor, Enrique C. Creel envío una carta al presidente Porfirio Díaz con fecha del 25 de abril de 1892. En ella, el miembro del grupo Terrazas, incitaba al general Díaz a intervenir en las elecciones y evitar el agravio político que significaba la reelección del gobernador vigente. Para fortalecer su súplica, hace alusión de un ambiente de caos y conflicto en Chihuahua y un pueblo unido en contra del gobernador Carrillo. Creel describe al rival político como una

que beneficiaba a los caciques locales Joaquín Chávez y Reyes Domínguez, el pueblo inconforme ante la imposición, decidió sublevarse y declarar su autonomía en el inicio del mes de diciembre. El ejército federal entonces decidió a intervenir. La conclusión de esta situación fue trágica; en el mes de octubre del siguiente año, 1892, el ejército decidió tras tomar el pueblo exterminar a casi todo los habitantes

23 Almada, 1950, p. 414.

24 Almada, 1950, p. 414.

25 Almada, 1950, p. 414. 
persona antipopular dispuesta a cualquier trasgresión de la paz para lograr su cometido. Enseguida se muestra un fragmento de la carta de Enrique Creel:

El actual gobernador Lauro Carrillo está preparando el golpe más duro hecho por un gobernador. Está intentando volver a ser gobernador y está usando todos los medios posibles. El grupo Terrazas no aceptará ni una lucha electoral. El gobernador impedirá el sufragio libre. Oprimirá y humillará a los pueblos y sería de temerse que se perturbara el orden público lo cual por conveniencia y por patriotismo debemos de evitar. Que si solo hubiera un candidato de acuerdo con el señor Díaz, y a que a ese candidato nos agrupemos todos para evitar divisiones en el estado, para no criar dificultades administrativas, y sobre todo para conservar la paz y la libertad. ${ }^{26}$

En la misma carta, el Sr. Creel indicó que su movimiento político anti-reeleccionista era exitosamente popular en todo el estado de Chihuahua. Escribía de una coalición política con eminentes personajes y sectores populares en Chihuahua, tal era el caso de las asociaciones de mineros del estado, trabajadores de gobierno y los vecinos de las poblaciones de Juárez, Chihuahua, Santa Rosalía, Jiménez y Parral. Enrique Creel continuó su mensaje de esta forma:

En Juárez está unánime el movimiento contra Carrillo, como en la capital, en Santa Rosalía, Jiménez y en Parral. Excepción hecha de los empleados que aunque discuten y opinan con nosotros no pueden hablar con libertad. Sin embargo, algunos magistrados y jueces, diputados y demás personas que pertenecen a la actual administración, nos han agradecido beneficios los cargos y empleados para unirse con nosotros. ${ }^{27}$

No obstante, la oposición política del grupo Terrazas no era del todo generalizada y popular. Las palabras de Creel parecen haber

26 AHUIA Colección Porfirio Díaz: CDP, Leg.: 017, Caja: 010, Docto.: 004819-21. 27 AHUIA Colección Porfirio Díaz: CDP, Leg.: 017, Caja: 010, Docto.: 004819-21.

Chinuahua Hoy, aÑo I 5 , NúM. I 5 (ENERo-Diciembre, 2017) 
sido solo un elemento retórico y argumentativo para reforzar su petición. Véase el porqué de la afirmación.

El 20 de mayo de 1892, vecinos del pueblo de Santa Rosalía, hoy ciudad Camargo, enviaron una carta al presidente Díaz en la cual le solicitaban que interviniera en las elecciones para que saliera victorioso el señor Félix Maceyra, quien en un periodo anterior, había ejercido el cargo de gobernador. La inclinación política de Maceyra era intermedia en el conflicto de intereses de los dos bandos en disputa. Los pobladores de Santa Rosalía trataron de comprometer la mediación directa de Porfirio Díaz aludiendo a una lealtad absoluta al presidente y un apoyo incondicional cuando este estaba en campaña electoral. El escrito da la oportunidad de especular que no todos los habitantes del estado eran simpatizantes del movimiento de los Terrazas. La carta fue enviada con una recolección de más 60 firmas de los vecinos del pueblo. En la carta se puede leer lo siguiente:

Santa Rosalía del Camargo, mayo 20 de 1892.

Al sr. Presidente de la República general de división Porfirio Díaz.

Primeramente aseguramos a usted con toda lealtad que nos hallamos de perfecto acuerdo, por aclamación general para que usted siga dirigiendo la nave del país que con acierto sin ejemplar ha gobernado y confesamos con toda franqueza y sinceridad, el ben que disfrutamos con la paz cimentada por usted con anhelo patriótico... y por esto mismo nos hemos arriesgado a distraer sus altas atenciones para ponernos en sus manos recatando su apoyo a fin de que haciéndole al estado un servicio importantísimo, se interponga con todas su merecida influencia para que en los nuevos comicios resulte el señor Félix Francisco Maceyra gobernador constitucional de nuestro estado por considerarlo digno de llegar las legítimas afiliaciones de nuestros pueblos, quedando siempre adictos a usted y bien dispuestos para atender sus respetables órdenes en cualesquier sentido tenemos la honra de ser suyos. ${ }^{28}$

28 AHUIA Colección Porfirio Díaz: CDP, Leg.: 017, Caja: 010, Docto.: 004857. 
El conflicto electoral y la imposibilidad de arreglarlo de manera pacífica llevaron a Porfirio Díaz a intervenir de manera directa. El presidente vio como única posible solución la promoción de un candidato desentendido de la lucha de los grupos terracista y carrillistas, pero leal a su persona. Por tanto, se decidió por designar como candidato al coronel Miguel Ahumada, originario del estado de Colima. Miguel Ahumada representaba una inteligente y pragmática posición de neutralidad ante la lucha por el poder. Porfirio Díaz no podía permitir el exceso de poderío de Terrazas, pero tampoco podía permitir que Lauro Carrillo continuara al frente del gobierno después de la revuelta promovida en Tomóchic meses antes.

Otro de los factores determinantes para que se haya dado la intervención del presidente en los comicios estatales, fue su pretensión de perpetuarse en la silla presidencial por un tiempo indefinido. Tras dos periodos presidenciales continuos de 1884 a 1888 y de 1888 a 1892, Porfirio Díaz logra modificar el artículo 78 de la Constitución en 1890, esto para lograr su reelección. Entonces, 1892 se convierte en un crucial movimiento político en el cual se pretendió borrar cualquier rastro de descontento o rebelión en Chihuahua contra la reelección presidencial. Al colocar en el ejecutivo estatal a un hombre leal a su persona, Díaz aseguraba la supresión de cualquier movimiento insubordinado de grupos políticos rivales. De ahí, la importancia de la jornada electoral a un nivel tanto regional como nacional.

Además, tras la revisión de los motivos anteriores, resulta ser que el nombramiento de Miguel Ahumada como candidato oficial no fue una simple contingencia. Si de nuevo se esboza la investigación de Luis Medina Peña, esta argumenta que la figura de los comandantes militares en los estados tenía entre sus funciones la de ser un mediador o arbitro en los conflictos regionales, siempre poniendo por delante la lealtad al poder central. La mesura estuvo un tanto generalizada a lo extenso de la república, y el estado de Chihuahua no fue la excepción. Por ello, el coronel Ahumada era la persona ideal para ocupar el cargo de gobernador. Era un militar neutral ante la lucha de los poderes regionales y apegado a 
los designios centrales, cuya función práctica era mediar entre los posibles conflictos de intereses de grupos dominantes. Al respecto sobre los mandos militares y su labor política, la obra de Medina Peña dice:

El comandante militar se transforma así, en cuanto brazo armado del Ejecutivo, en el árbitro de los conflictos locales con el resultado que muchos de ellos se convierten en gobernadores de los estados. Se puede decir que el empalme entre la esfera federal y la esfera de los estados tiende a regularse, caso por caso, a partir de las tensiones existentes en el interior de las regiones en las cuales el poder federal, representado informalmente por el comandante militar, interviene como mediador con el resultado de que las regiones comienzan a empalmarse con el centro, con la federación. ${ }^{29}$

Medina Peña considera que las políticas intervencionistas del ejecutivo federal en los asuntos de los estados, se vuelven una recurrente tendencia a partir de la década de 1890. La misma medida pretendía un mejor control del centro del país sobre las autoridades municipales y de distrito, lo que a corto plazo hizo presente la existencia de dos tipos de élites políticas, las regionales y la central. ${ }^{30}$ Por tal razón, la elección chihuahuense de 1892 puede ser entendida como la manifestación de estos dos grupos de poder, enfrentados claro está, por el dominio político del estado.

En el mes de abril de 1892 el sobrino de Luis Terrazas, Enrique Creel, visitó la ciudad de México por motivos de agenda política. En esos días tuvo una reunión con el presidente Porfirio Díaz y el Club Político Central. Cabe mencionar que desde esa junta ya se vislumbraba el triunfo del coronel Miguel Ahumada. Una de las señales más claras para presagiarlo fue que el señor Miguel Ahumada había sido elegido por la mayoría del club como el indicado para la candidatura. Para el sobrino de Terrazas, la elección de Ahumada era un acertado movimiento hecho bajo parámetros legales y democráticos. En la carta no parece molesto por la de-

29 Medina Peña, 2012, p. 160.

30 Medina Peña, 2012, p. 159. 
cisión, al contrario, auguraba el triunfo de lo que llamó "su causa" en contra de Carrillo. Abajo se muestra un fragmento de la carta de Creel dirigida a su padrino Luis Terrazas informándolo de lo acordado:

Abril 3 de 1892, México.

Sr. Luis Terrazas:

El primero del corriente se instaló la asamblea general de Club Político Central y en una forma internamente correcta y democrática se hizo la elección del candidato para gobernador del estado en la persona del coronel Miguel Ahumada.

Esta postulación ha sido muy bien aceptada en todo el estado, a juzgar por los mensajes de las personas de Juárez, Rosales, Meoqui, Santa Rosalía, Jiménez, Allende, Parral, Urique, Chinipas... ${ }^{31}$

Para el día 19 de abril, el coronel Miguel Ahumada ya estaba enterado de la elección hecha en el centro del país a favor de su persona. Pronto entabló correspondencia con el presidente Porfirio Díaz. Entre las primeras cosas fue el agradecerle por la candidatura y ponerse a las órdenes que el presidente Díaz dispusiera. Desde esta carta se puede observar un Ahumada apegado a los estipulados de la Ciudad de México. Aquí parte de una de esas cartas:

Chihuahua, 19 de abril de 1892.

Señor General Porfirio Díaz.

Muy respetable señor.

Como dije a usted por telégrafo acaba de venir a verme una comisión compuesta de más de veinte personas de las permanentes de esta ciudad a fin de manifestarme que el Club Central se había fijado en mí como candidato para el gobierno de este estado en el próximo periodo. Yo simplemente les manifesté mi agradecimiento por el honor inmerecido que me hacían, sin decir si aceptaba o no los trabajos que emprendieron en mi favor porque como no he re-

31 AHUIA Colección Porfirio Díaz CPD Leg: 017 Caja 011 Docto. 000567-68.

Chinuahua Hoy, aÑo I 5 , NúM. I 5 (ENERo-Diciembre, 2017) 


\section{Mario Alejandro Domínguez CruZ}

cibido indicaciones de usted a este respecto, de propósito hice esa omisión.

Después vinieron aisladamente varias personas a preguntarme si ya estaba yo autorizado por usted para dejar lanzar al público mi candidatura y yo me he concretado a contestarles lo que es verdad, que ignoro la opinión de usted a este respecto y que en todos los trabajos que se han hecho me he tenido yo ni el menos participio.

Me apresuro a comunicar a usted esto porque obro en su superior conocimiento, manifestándole una vez más para lo que se sirva determinar, que ningún paso daré sin que usted me lo ordene previamente. ${ }^{32}$

La comunicación entre el presidente Díaz y el candidato Ahumada durante la campaña fue constante. En las cartas entre ambos, se puede leer sobre el envío de órdenes y el acatamiento de las mismas. Entre el grupo de correspondencia resalta una carta del 14 de abril de 1892. En ella, Ahumada escribe sobre el apoyo dado a su candidatura por un grupo de empresarios, hacendados, mineros, industriales y ciudadanos importantes. Entre otros asuntos, reafirmó su compromiso de solo cumplir los mandatos del presidente y no entablar coalición de intereses con ningún grupo o persona, y sucedió cuando el coronel Ahumada escribió que:

[En] cumplimiento a su obediencia he seguido con esta posición, la prudencia y el atamiento que me ha asignado, sin aceptar ni candidatura ni comprometerme en lo más mínimo con ninguna persona... ${ }^{33}$

Entre otros asuntos avisó de la estadía en Chihuahua del capitán Manuel Cárdenas y de su estrecha relación con el gobernador Lauro Carrillo. Ahumada sintió su presencia como una amenaza al endeble orden en la capital de estado. A final de la carta le sugiere al presidente Díaz que era conveniente cambiar de lugar a

32 AHUIA Colección Porfirio Díaz CPD Leg: 017 Caja 011 Docto. 005119.

33 AHUIA Colección Porfirio Díaz CPD, Leg: 017, Caja: 011, Docto.: 005121. 
Cárdenas para evitar cualquier pormenor. En la carta puede seguir leyéndose lo siguiente:

Chihuahua, Chihuahua. Abril 14 de 1892

Sr. General Porfirio Díaz, México.

Me favorece la siempre grata de usted fecha 8 del actual, puntualmente con la que me acompaña dirigido a los señores Bermejillo, José V. Del Collado, Benecke Lucevores, Luis Larie, José de Teresa y Miranda, Valentin Whink por comerciantes, hacendados, industriales y mineros residentes del estado y de cuyo contenido me he impuesto determinantemente llegado el caso proceder como se sirve indicarme, pues si es la voluntad de usted el que yo sea favorecido con el honroso puesto de gobernador de este estado en el próximo periodo constitucional. Seguiré en todo las indicaciones que usted me haga el favor comunicarme... Existe en esta ciudad un capitán segundo Manuel Cárdenas considerado en depósito y al servicio del gobernador Carrillo; a fin de evitar ulteriores males que este pudiera ocasionar de una manera embozada en la cuestión electoral que se agita, sería muy conveniente que fuera cambiado de aquí llevándolo a otra parte fuera del estado siempre que así lo estime usted señor presidente. $^{34}$

Miguel Ahumada tomó posesión del cargo de gobernador el día 4 de octubre de 1892 y siguió ejerciéndolo hasta el año de 1904. A pesar de la intervención del gobierno central en los comicios de Chihuahua, los ánimos alcanzaron un grado de efervescencia nunca antes visto. Tanto así, que un mes después de la designación de Ahumada como candidato oficial, en mayo, los directores de los dos principales periódicos locales, Pablo Ochoa (aliado del grupo Terrazas) de El Norte y Luis Díaz Couder (aliado del grupo Carrillo) de El Diario de Chihuahua, decidieron arreglar sus diferencias políticas, personales y editoriales en un duelo con armas de fuego. El resultado del enfrentamiento fue la muerte de Pablo Ochoa. ${ }^{35}$ Después de esto, sería cuestión de que el tiempo

34 AHUIA Colección Porfirio Díaz CPD, Leg: 017, Caja: 011, Docto.: 005121.

35 Almada, 1950, p. 414.

Chinuahua Hoy, aÑo I 5 , Núm. I 5 (ENERo-Diciembre, 2017) 
pasara para que los ánimos políticos en Chihuahua fueran reduciéndose gradualmente, hasta alcanzar el concilio de los intereses de ambas partes.

La administración del Coronel Ahumada es reconocida hasta la actualidad como un periodo de estabilidad entre las fuerzas políticas del estado de Chihuahua. Sobre los intereses de grupos locales dominaron las decisiones de la Ciudad de México. También su administración es recordada por su espíritu progresista, pues durante su mandato se terminó de construir el actual Palacio de Gobierno, el antiguo teatro de los Héroes, se creó la oficina central de Registro Civil, se derogaron las alcabalas, se formaron consorcios empresariales y se introdujeron vías ferroviarias secundarias a pequeñas poblaciones. ${ }^{36}$ Al respecto Francisco R. Almada comentó de la administración de Miguel Ahumada:

La administración del coronel Miguel Ahumada al frente del estado comprende un periodo fuertemente constructivo dentro del régimen porfirista y el equilibrio entre los grupos políticos apasionados, el terracismo y el carrillismo, neutralizados con verdadera inteligencia por un hombre como Ahumada, que supo imponerse juiciosamente sobre sus pasiones y los intereses bastardos y desarrollar un programa de gobierno que es recordado con cariño por todos los chihuahuenses... supo conciliar estas cualidades y su acción de mando para hacerse respetar de todos y gobernar a Chihuahua neutralizando pasiones políticas y tratando a todas las clases sociales por igual. ${ }^{37}$

Para lograr las paces entre las élites políticas del centro del país y el grupo más poderoso de Chihuahua, los Terrazas-Creel, fue fundamental la intervención del sobrino de don Luis Terrazas. Enrique Creel logró convertirse al paso de los años en una de las figuras más cercanas al presidente Díaz. Junto con José Yves Limantour, Creel era considerado uno de los imprescindibles en el gabinete federal, y al mismo tiempo asumido como uno de los más

36 Almada, 1950, p. 429.

37 Almada, 1950, p. 426. 
inteligentes científicos porfirianos. Entre sus cargos estuvieron el de ser secretario de relaciones exteriores además de embajador de México en los Estados Unidos.

Tras la conciliación de periferia-centro, que significaba más que nada, las paces entre Luis Terrazas y Porfirio Díaz, fue posible de nuevo el ascenso del grupo Terrazas al poder ejecutivo estatal. En 1904, el general Luis Terrazas fue elegido como gobernador de Chihuahua y en 1907, tras una candidatura polémica y una jornada electoral poco participativa, su sobrino Enrique Creel fue electo gobernador del estado; se vio forzado a dejar el cargo en el año de $1910{ }^{38} \mathrm{Su}$ antipopular administración es considerada una de las principales causas del alzamiento de fuerzas rebeldes al inicio de la revolución en el estado de Chihuahua.

\section{V}

Para concluir, lo siguiente: alrededor de todo este trabajo giraron cinco documentos históricos que contextualizaron el funcionamiento del sistema electoral mexicano a finales del siglo XIX. El manejo de las fuentes históricas permite al historiador demostrar la subsistencia de los vínculos solidarios desde el virreinato hasta las postrimerías del siglo XIX. Hasta este punto, la evidencia expuesta y su respectiva interpretación dan la razón a los trabajos antes citados sobre el proceso electoral mexicano.

Asimismo, el estudio de caso demuestra la inoperatividad correcta del transcurso de votaciones. La elección de 1892 sugiere que ser electo como gobernador del estado no dependía de quién tuviera más votos en las urnas. El día de la elección era concebido como pura formalidad, y en todo caso, solo legitimaba y formalizaba el triunfo del candidato oficial. Lo que determinó el desenlace del proceso se llevó a cabo tras bambalinas. La correspondencia, reuniones y decisiones a puerta cerrada pesaron más que lo sufragios, y decidieron un candidato ganador antes de la jornada electoral. Es así que las elecciones de entonces se deben de interpretar como resultado del desarrollo histórico de México. Eran

38 Almada, 1950, p. 441.

Chinuahua Hoy, año is, Núm. Is (ENero-diciembre, 2017) 
acorde al ritmo orgánico de la realidad política, eran prácticas y ante todo, bien o mal, funcionaban.

Por último, dentro del ejemplo se puede observar una encarnizada lucha de grupos oligarcas, la cual casi llegó a un enfrentamiento violento. La solución al conflicto fue posible gracias a la intervención directa y sistematizada del presidente de la República Porfirio Díaz y de la élite central. La injerencia de estos dos fue determinante, y se debió a factores tan decisivos como lo fueron la elección presidencial del mismo año, además, del intentar solucionar la rebelión serrana de Tomóchic y el posible enfrentamiento armado entre los grupos contrincantes. Ninguno de los clanes regionales triunfó con el resultado de las elecciones del año de 1892, en cambio sí, el resultado benefició a la capital del país.

La jornada electoral debe de ser entendida como un brillante movimiento político. En el tablero de juego, las piezas fueron movidas de tal manera que el presidente Díaz pudo poner en jaque a sus adversarios. Fue meticuloso y conciliador. Esa es, por tanto, la importancia de tales elecciones en Chihuahua, ya que marcaron el futuro político de estado por más de doce años. Por sus características puede ser considerada la elección más importante del porfiriato en Chihuahua y su efecto debe de ser estudiado aún más a fondo.

Con Ahumada como gobernador, era el presidente de la República quien tuvo la última palabra. También, la neutralidad política que otorgaba el gobernador Miguel Ahumada cimbró un lapso de paz que permitió el desarrollo económico del estado. Hasta hoy, en Chihuahua, el nombre de Ahumada es reconocido como sinónimo de prudencia y contrapeso político ante la presión de un temible gigante, como lo fue Luis Terrazas y sus aliados.

\section{BIBLIOGRAFÍA}

Almada, Francisco R. (1968). Diccionario de historia, geografía y biografía chihuahuense. México: UACH.

Almada, Francisco R. (1950). Gobernadores del estado de Chihua-

hua. México: Imprenta de la Cámara de Diputados. 
Braudel, Fernand (2007). La larga duración, en la historia y las ciencias sociales, capítulo 3, Alianza Editorial, Madrid, 1979 (4. ${ }^{\circ}$ edición). Relaciones Internacionales, 0(5). Recuperado de http://www.relacionesinternacionales.info/ojs/index. php?journal=Relaciones_Internacionales\&page=article\&op=vie w\&path $\% 5 B \% 5 D=53 \&$ path $\% 5 B \% 5 D=47$

Garner, Paul (2011) El Porfiriato como Estado-nación moderno: ¿paradigma o espejismo? En Estado, Constitución y Reforma, 1821-1908 (276-304). México: FCE.

Guerra, François Xavier. (1989). Del antiguo régimen a la Revolución. México: FCE.

Medina Peña, Luis (2012). La invención del sistema político mexicano. Forma de gobierno y gobernabilidad en México en el siglo XIX. México: FCE.

Medina Peña, Luis (2011). México: Una modernización tardía e incompleta. En Estado, Constitución y Reforma, 1821-1908 (2161). México: FCE.

Knight, Alan (2010). La Revolución mexicana. México: FCE.

Rice, Jacqueline Ann (1979). The porfirian political elite. Life patterns of the delegates to the 1892 convention. Tesis presentada en satisfacción parcial de los requisitos para obtener el grado de Doctor en Filosofía en Historia por la Universidad de California, Estados Unidos.

Ponce Alcocer, Ma. Eugenia. (2000). La elección presidencial de Manuel González, 1878-1880. México: UIA.

\section{ARCHIVOS HISTÓRICOS}

Área de colecciones especiales de la Secretaría de Cultura del estado de Chihuahua.

Archivo histórico de la Universidad Iberoamericana (AHUIA), Colección Porfirio Díaz. 